\title{
Clinical practice guidelines for patients with polymyalgia rheumatica: the need for an active involvement of all stakeholder is still unmet
}

\author{
C. Manzo
}

Azienda Sanitaria Locale Napoli 3 sud, Rheumatologic Outpatient Clinic, Health Distict no. 59, Sant'Agnello (NA), Italy

$\mathrm{D}$ ear Editor,

I have read with great interest the article entitled "The Italian Society of Rheumatology clinical practice guidelines for the management of polymyalgia rheumatica", published in the latest issue of Reumatismo (1).

In the introduction, the Authors report the different incidence of polymyalgia rheumatica (PMR) observed in two Italian geographical areas, with yearly data between 0,12 to 0,27 cases for 1,000 people $(2,3)$. To this day, Italian epidemiological studies on PMR can be counted on the fingers of one hand.

It is common knowledge that the general practitioner (GP) is usually the first physician who examines the PMR patient. Many PMR patients are not referred to rheumatologists or are referred only in the presence of diagnostic or therapeutic issuesatypical findings such as erythrocyte sedimendation rate $[E S R]<30 \mathrm{~mm} / 1 \mathrm{~h}$ at the time of diagnosis or PMR scarcely responding to prednisone therapy or with severe systemic manifestations, for example (4-6). In a study from the UK, only $17 \%$ of patients with PMR was referred to a rheu-

In the Italian National Health System, outof-hospital public specialists add an intermediate professional role between general practice and secondary and tertiary care centre. This role is absent in other national health systems (8).

In 2009, we published the data of incidence

$(13,500$ inhabitants) in the Sorrento peninmatologist (7).

sula. In this study, carried out in close collaboration with all local GPs, the diagnosis of PMR was in line with Healey's criteria, but ESR $<40 \mathrm{~mm}$ at the time of diagnosis was not considered as an exclusion criterion if all other criteria were present. A yearly incidence of 2.3 cases $/ 1,000$ persons aged over 50 years between 2000 and 2007 was found (9). I recently revised all data in this database (10).

Together with other researchers I suggested that all future epidemiological studies should also consider territorial data, in addition to hospital and university ones because the incidence of PMR could be much higher than commonly thought (8).

This is a critical point. What is PMR for the rheumatologist is the same for GP? Is it possible that the out-of-hospital public rheumatologist visits many more patients affected by PMR than the hospital or university rheumatologist? It is possible, because PMR is almost always an outpatient disease.

Unfortunately, there were no no out-ofhospital public rheumatologists among the members of the working group involved in the development of the recommendations for clinical and laboratory assessments, treatment and follow-up of PMR patients reported in the above-mentioned article. Only one GP was invited.

I think that this was a missed opportunity. No doubt, the need for an active involvement of all stakeholder is still unmet.

\section{Conflict of interest}

The author declares no confict of interest. 


\section{REFERENCES}

1. Ughi N, Sebastiani GD, Gerli R, Salvarani C, Parisi S, Ariani A, et al. The Italian Society of Rheumatology clinical practice guidelines for the management of polymyalgia rheumatica. Reumatismo. 2020; 72: 1-15.

2. De Socio A, Perrotta FM, Grasso GM, Lubrano E. Incidence of rheumatoid arthritis, psoriatic arthritis and polymyalgia rheumatica in an inland area of central Italy: results of the CAMPO-RHE study. Postgrad Med. 2018; 130: 137-41.

3. Salvarani C, Macchioni PL, Zizzi F, Rossi F, Castri C, Capozzoli N, et al. Epidemiologic and immunogenetic aspects of polymyalgia rheumatic and giant cell arteritis in northern Italy. Arthritis Rheum. 1991; 34: 351-6.

4. Helliwell T, Hider SL, Mallen CD. Polymyalgia rheumatica: Diagnosis, prescribing and monitoring in general practice. Br. J. Gen. Pract. 2013; 63: e361-e366.

5. Manzo C, Natale M, Traini E. Diagnosis of polymyalgia rheumatica in primary health care: favoring and confounding factors. A cohort study. Reumatologia. 2018; 56: 131-9.

6. Mathew R, Rashid A. Polymyalgia rheumatica in primary care: managing diagnostic uncertainty. BMJ. 2015; 351: h5199.
7. Barraclough K, Liddell WG, Du Toit J, Foy C, Dasgupta B, Thomas M, et al. Polymyalgia rheumatica in primary care: A cohort study of the diagnostic criteria and outcome. Fam. Pract. 2008; 25: 328-3.

8. Sobrero A, Manzo C, Stimamiglio A. The role of general practictioner and out-of-hospital public rheumatologist in the diagnosis and follow-up of the patient with polymyalgia rheumatica. Reumatismo. 2018; 70: 44-50.

9. Manzo C, Balduccelli M, Cappiello F, De Cesare M, Gargiulo L, Mellino A, et al. Epidemiologia della polimialgia reumatica nel comune di Massa Lubrense. Trends Med. 2009; 9: 101-5.

10. Manzo C. Incidence and prevalence of Polymyalgia Rheumatica (PMR): the importance of the epidemiological context. The Italian case. Med Sci (Basel). 2019; 7: 92. doi: 10.3390/medsci7090092.

11. Manzo C, Balduccelli M, Cappiello F, De Cesare M, Gargiulo L, Mellino A, et al. Epidemiologia della polimialgia reumatica nel comune di Massa Lubrense. Trends Med. 2009; 9: 101-5.

12. Manzo C. Incidence and prevalence of Polymyalgia Rheumatica (PMR): the importance of the epidemiological context. The Italian case. Med Sci (Basel). 2019; 7: 92. doi: 10.3390/medsci7090092. 